\title{
Presurgical levels of circulating cell-derived microparticles discriminate between patients with and without transfusion in coronary artery bypass graft surgery
}

\author{
Wenche Jy, PhD, ${ }^{a}$ Orlando Gómez-Marín, MSc, PhD, ${ }^{b}$ Tomas A. Salerno, MD, ${ }^{c}$ Anthony L. Panos, MD, \\ Donald Williams, MD, ${ }^{\mathrm{c}}$ Lawrence L. Horstman, BS, ${ }^{\mathrm{a}}$ and Yeon S. Ahn, MD ${ }^{\mathrm{a}}$
}

\begin{abstract}
Objectives: Improved understanding of presurgical risk factors for transfusions will lead to reduction in their number and related complications. The goal of this study is to identify these factors in coronary artery bypass graft $(\mathrm{CABG})$ surgery.
\end{abstract}

\begin{abstract}
Methods: Presented herein are results of analyses of data from an ongoing study of transfusion in CABG surgery. Of 122 patients, 81 received transfusion (Tx) and 41 did not (NoTx). In addition to routine tests, presurgical levels of microparticles from platelets (PMPs), red cells (RMPs), and other lineages were assayed.

Results: The Tx and NoTx groups were similar with respect to most presurgical variables but differed in distribution of gender, blood type, diabetes prevalence, activated partial thromboplastin time (aPTT), hemoglobin (HGB), and microparticle levels. Stepwise multiple logistic regression was used to evaluate presurgical variables and to develop a model to assess risk factors for transfusion. CD41 ${ }^{+}$PMP and CD235 ${ }^{+}$RMP levels were found to be the main risk factors for transfusion. The Model's discriminating ability was assessed using receiver operating characteristic curve analysis, which showed that the area under the model curve ( \pm standard error) was $0.86 \pm 0.04$ (95\% confidence interval, 0.77-0.94). According to the model, patients with higher presurgical levels of circulating CD41 ${ }^{+}$PMP, CD235a ${ }^{+}$RMP, and HGB, as well as a shorter aPTT, are less likely to receive transfusion(s).
\end{abstract}

Conclusions: Presurgical levels of CD $41^{+}$PMPs and CD235a ${ }^{+}$RMPs are the main risk factors for transfusion in CABG, followed by HGB and aPTT. (J Thorac Cardiovasc Surg 2015;149:305-11)

See related commentary on pages 312-3.

Blood transfusion saves many lives but is associated with higher incidence of adverse outcomes compared to no transfusion. ${ }^{1,2}$ The adverse effects of transfusion include higher incidence of postsurgical infections, longer hospital stay, poorer surgical outcomes, and higher mortality. ${ }^{3-7}$ There is a growing interest in how blood transfusion should be better managed. ${ }^{1,7}$

A number of risk factors for transfusion during surgery have been identified, including older age, female gender,

\footnotetext{
From the Wallace H Coulter Platelet Laboratory, ${ }^{\text {a }}$ Division of Hematology and Oncology, Department of Medicine, Departments of Public Health Sciences, Medicine, and Pediatrics, ${ }^{\mathrm{b}}$ and Division of Cardiothoracic Surgery, ${ }^{\mathrm{c}}$ Department of Surgery, Miller School of Medicine, University of Miami, Miami, Fla.

This work was supported by grants from the National Institutes of Health, National Heart, Lung and Blood Institute (1R01HL098031), and the Wallace H. Coulter Foundation.

Disclosures: Authors have nothing to disclose with regard to commercial support.

Received for publication March 24, 2014; revisions received Aug 29, 2014; accepted for publication Oct 6, 2014 .

Address for reprints: Wenche Jy, PhD, 1600 NW 10th Ave. R-36A, Miller School of Medicine, University of Miami, Miami, FL 33136 (E-mail: wjy@ med.miami.edu). $0022-5223 / \$ 36.00$

Copyright (C) 2015 by The American Association for Thoracic Surgery http://dx.doi.org/10.1016/j.jtcvs.2014.10.042
}

weight, renal insufficiency, abnormal left ventricle ejection fraction, emergency surgery, longer cardiopulmonary bypass (CPB) time, and low presurgical hemoglobin levels. ${ }^{8-11}$ In addition, several parameters of coagulation and platelet status have been shown to be associated with surgical transfusion. ${ }^{12-15}$

Cell-derived microparticles are small membranous vesicles of size $<1.0 \mu \mathrm{m}$, released during cell activation and apoptosis. Evidence is accumulating that circulating microparticles play an important role in hemostasis. ${ }^{16}$ They are capable of accelerating blood coagulation and enhancing platelet aggregation and adhesion. ${ }^{16-18}$ Clinical studies have revealed that patients who are deficient in microparticle generation are prone to bleeding episodes. ${ }^{17,19}$ Patients with immune thrombocytopenic purpura who had high levels of circulating microparticles were protected against bleeding compared to those with lower levels of microparticles and similarly low platelet counts. ${ }^{20}$ The role of microparticles as a risk factor for transfusion has not been previously reported.

The major aim of the present analysis is to assess the presurgical levels of microparticles as well as clinical and sociodemographic characteristics as risk factors for transfusion during and/or after coronary artery bypass graft (CABG) surgery. 


$$
\begin{aligned}
& \text { Abbreviations and Acronyms } \\
& \text { AUC }=\text { area under the curve } \\
& \text { aPTT }=\text { activated partial thromboplastin time } \\
& \text { CABG }=\text { coronary artery bypass graft } \\
& \text { CPB }=\text { cardiopulmonary bypass } \\
& \text { Cy5 } 5 \text { Cyanine } 5 \\
& \text { EMP }=\text { endothelium-derived microparticle } \\
& \text { FITC }=\text { fluorescein isothiocyanate } \\
& \text { HGB }=\text { hemoglobin } \\
& \text { LMP }=\text { leukocyte-derived microparticle } \\
& \text { MP }=\text { microparticle } \\
& \text { PE }=\text { phycoerythrin } \\
& \text { PMP }=\text { platelet-derived microparticle } \\
& \text { PT }=\text { prothrombin time } \\
& \text { QC }=\text { quality control } \\
& \text { RBC }=\text { red blood cell } \\
& \text { RMP }=\text { red cell-derived microparticle } \\
& \text { ROC }=\text { receiver operating characteristic } \\
& \text { TEG }=\text { thromboelastography }
\end{aligned}
$$

\section{MATERIALS AND METHODS \\ Patient Population}

We present the results of analyses of data obtained from an ongoing randomized clinical trial on transfusion practice in patients undergoing $\mathrm{CABG}$ surgery (NCT01185600). The main hypothesis of the original trial is that transfusion of washed packed cells results in improved surgical outcomes and lower levels of proinflammatory biomarkers compared to transfusion of unwashed packed cells. At presurgery, participants are randomized to 1 of these 2 groups, but some of them end up not needing a transfusion. As a part of the study, cell-derived microparticles are assayed for all participants. Results presented in this manuscript are limited to presurgical data used to compare patients who received transfusion(s) versus those who did not.

Inclusion/exclusion criteria. All patients admitted to the University of Miami medical center for CABG surgery are screened as potential study participants. The exclusion criteria include (1) age $<20$ years, (2) pregnancy, (3) refusal to accept blood transfusion, (4) combined CABG and other procedures such as valve replacement, (5) emergency surgery, and (6) known bleeding disorders. Informed written consent is obtained from each eligible patient who agrees to participate in the study.

Transfusion criteria. Each participant is classified as either a highrisk or non-high-risk patient. The former class includes patients with renal failure, or on clopidogrel (Plavix) within 5 days prior to surgery, or with ejection fraction $<20 \%$. The transfusion criteria are as follows: (1) for the high-risk group, hematocrit $\leq 28 \%$; (2) for the non-high-risk group, hematocrit $\leq 25 \%$; or (3) for any patient with active blood loss and unstable vital signs (eg, falling blood pressure, tachycardia, or hypoxemia), the surgical team uses clinical judgment for transfusion.

Preoperative medications. Coumadin and clopidogrel (Plavix) are discontinued at least 5 days prior to surgery. Aspirin is continued without interruption according to protocol. Those who did not stop Plavix within 5 days are considered in the high-risk group for bleeding (see above transfusion criteria). Heparin is discontinued 5 hours before surgery and resumed 24 hours after surgery with prophylactic subcutaneous daily injection. For the present analyses, no special consideration was given to numerous other drugs taken for various comorbidities, but all are recorded in the database.
A total of 122 patients undergoing $\mathrm{CABG}$ have been recruited for the study. Of them, 81 received red blood cell (RBC) transfusion(s) during and/or after surgery (Tx Group), whereas the remaining 41 did not receive any transfusion (NoTx Group). The present report is concerned with the assessment of presurgical characteristics as risk factors for transfusion in patients undergoing $\mathrm{CABG}$ surgery.

\section{Laboratory Studies}

Routine complete blood count, platelet, coagulation tests, and blood chemistry are performed before surgery and as needed postoperatively. Special studies performed are listed below.

\section{Blood Sampling and Handling}

At 1 hour prior to surgery, using a 21-gauge needle, venous blood samples are drawn into plastic vacuum tubes containing sodium citrate (Vacuettes; Greiner Bio-One, Monroe, NC). To minimize tissue factor contamination, the first tube is used for routine lab tests and subsequent blood samples are used for microparticle assays. Samples are centrifuged at $1800 \times g$ for 15 minutes within 1 hour of collection to minimize release of microparticles ex vivo. All samples are maintained at room temperature. After centrifugation, supernatants containing the microparticles (platelet-poor plasma) are removed for flow cytometric assays, within 4 hours after blood drawing.

\section{Materials for Flow Cytometry}

The sources of monoclonal antibodies and markers are as follows. Beckman-Coulter (Brea, Calif): anti-CD41-fluorescein isothiocyanate (FITC) (catalog no. IM0649U), anti-CD42B-FITC (catalog no. IM0648U), anti-CD45-phycoerythrin (PE) (catalog no. IM2078U), and CD235a-PE (catalog no. IM2211U); Becton-Dickinson (Franklin Lakes, NJ): anti-CD11B-PE-Cyanine 5 (Cy5) (catalog no. 555389) and CD62E-PE-Cy5 (catalog no. 550040); e-Bioscience (San Diego, Calif): anti-CD144-PE (catalog no. 12-1449-80); Sekisui Diagnostics (Stamford, Conn): anti-tissue factor-FITC (catalog no. 4508CJ); and Sigma-Aldrich (St Louis, Mo): annexin V-FITC (catalog no. 072M4060).

\section{Microparticle Assays by Flow Cytometry}

Microparticle species and subtypes are assayed by flow cytometric methods, briefly as follows. For labeling of microparticles, $20 \mu \mathrm{L}$ of platelet-poor plasma are incubated with $4 \mu \mathrm{L}$ of monoclonal antibodies specific for each cell lineage. The monoclonal antibodies used are anti-CD235a, for red cell-derived microparticles (RMPs); anti-CD41-FITC or CD31-PE plus CD42-FITC $\left(\mathrm{CD} 31^{+} / \mathrm{CD} 42^{+}\right)$, for 2 phenotypes of platelet-derived microparticles (PMPs); anti-CD144-PE, CD62E-PE-Cy5, or CD31-PE plus $\mathrm{CD} 42$-FITC $\left(\mathrm{CD} 31^{+} / \mathrm{CD} 42^{-}\right)$, for 2 phenotypes of endotheliumderived microparticles (EMPs); anti-CD45-PE or CD11b-PE-Cy5, for leukocyte-derived microparticles (LMPs); anti-tissue factor (TF)-FITC for $\mathrm{TF}^{+}$microparticles. Annexin $\mathrm{V}^{+}$-derived microparticles are labeled by 2 $\mu \mathrm{L}$ of annexin V-FITC (Sigma) plus $2.4 \mu \mathrm{L}$ of $40 \mathrm{mM} \mathrm{CaCl}_{2}$. Next, the samples are gently shaken (60 rpm) for 20 minutes to ensure optimal antibody binding and then diluted with $500 \mu \mathrm{L}$ of $0.9 \% \mathrm{NaCl}$ plus $10 \mathrm{mM}$ HEPES (4-(2-hydroxyethyl)-1-piperazineethanesulfonic acid), $\mathrm{pH}$ 7.4. Additional details on flow cytometric procedures are described in Jy et al. ${ }^{18}$

\section{Thromboelastography (TEG)}

For TEG assays, all blood samples are tested not more than 3 hours after drawing. A total of $330 \mu \mathrm{L}$ of whole blood is added to a well containing $20 \mu \mathrm{L}$ of $200 \mathrm{mM} \mathrm{CaCl}_{2}$ to initiate coagulation. The TEG parameters of interest in this study are as follows: $R$, lag time to initial fibrin formation; $K$, time to amplitude of $20 \mathrm{~mm}$; $A$, angle, reflecting the initial rate; MA, maximum amplitude, reflecting platelet function; and coagulation index, which is a composite global measure, calculated by the following formula:

Coagulation index $=-0.2454 R+0.0184 K+0.1655 \mathrm{MA}-0.0241 A-5.022$. 


\section{Other Special Assays}

Shear-induced platelet adhesion is measured in a cone-and-plate device (Impact R; DiaMed, Cressier, Switzerland) as previously described. ${ }^{18}$ Lipid oxidation status of microparticles is determined by the method of 8-isoprostane (Cayman Chemical Co, Ann Arbor, Mich) in the plateletpoor plasma.

\section{Quality Control (QC)}

All procedures in our laboratory have been well standardized. Flow cytometry is calibrated daily and QC samples are run routinely. QC control data for our method of microparticle count by flow cytometry yields coefficients of variation for intra-analysis (precision) and interanalysis (accuracy) of $1.8 \%$ and $7.9 \%$, respectively.

\section{Statistical Methods}

The statistical techniques used for comparing the Tx and NoTX groups included independent sample $t$ tests for variables with normal or approximately normal distribution, Mann-Whitney tests for variables with skewed distributions and for ordinal variables, and $\chi^{2}$ tests or Fisher exact tests for discrete variables.

Association between the variables was assessed using, as appropriate, either Pearson or Spearman rank correlation analysis. Highly correlated variables are not expected to remain together in a multivariable model or in a model derived using techniques such as stepwise regression.

\section{Risk Assessment Models}

Assessment of variables as risk factors for transfusion was performed in several steps. First, separate bivariate logistic regression models were considered using as the independent variable each of the variables in Tables 1 and 2. For each model, the dependent dichotomous variable was coded as 1 for participants who received blood transfusion(s) at any time during their hospitalization and as 0 for those who did not. Subsequently, a multivariate model was considered to assess which of the variables in step 1 remained as significant risk factors for transfusion after adjusting for the effect of the remaining variables in the model. Then, given the relatively small sample size $(\mathrm{n}=122)$ and the relatively large number of available variables, we sought to develop a more parsimonious model with similar or greater discriminating power than the multiple logistic regression model developed in step 2. For this purpose, we used a stepwise logistic regression approach that included as initial variables all the independent variables included in the multivariable model.

At each step in the logistic model development process, the fundamental requirement of logistic regression was evaluated. That is, we assessed the linearity of the logit with respect to each of the continuous variables in the model. Following this was the assessment of the discriminating ability of the models using receiver operating characteristic (ROC) curve analyses. For each of the variables included in a model, the area under the corresponding ROC curve (AUC) and its $95 \%$ confidence interval (CI) were calculated. Each AUC is an indicator of the ability of the corresponding variable to discriminate between patients who were and those who were not transfused.

In all the logistic regression analyses, for each independent continuous variable with a relatively narrow range, such as HGB and aPTT, the odds

TABLE 1. Presurgery sociodemographic, anthropometric, and clinical characteristics by transfusion group

\begin{tabular}{|c|c|c|c|c|c|}
\hline Characteristic & $\operatorname{NoTx} \operatorname{group}(n=41)$ & Tx group $(n=81)$ & Mean difference (SD) & $\mathbf{9 5} \% \mathrm{CI}$ & $P$ value \\
\hline Age (y) & $61.7(8.8)$ & $62.1(9.6)$ & $-0.6(9.4)$ & $-4.2,3.0$ & $.790^{*}$ \\
\hline BMI & $28.6(4.6)$ & $28.1(4.6)$ & $0.5(5.36)$ & $-1.6,2.5$ & $.921 *$ \\
\hline Gender, n (\%) & & & & & $.017 *$ \\
\hline Female & $5(12.2)$ & $26(32.1)$ & - & - & \\
\hline Male & $36(87.8)$ & $55(67.9)$ & - & - & \\
\hline Race, n (\%) & & & & & $.521^{*}$ \\
\hline White & $33(80.5)$ & $61(75.3)$ & - & - & \\
\hline Other & $8(19.5)$ & $20(24.7)$ & - & - & \\
\hline Blood type, n (\%) & & & & & $.032 *$ \\
\hline Type O & $11(26.8)$ & $38(46.9)$ & - & - & \\
\hline Other & $30(73.2)$ & $43(53.1)$ & - & - & \\
\hline \multicolumn{6}{|l|}{ Medical history, n (\%) } \\
\hline Myocardial infarction & $28(68.3)$ & $62(76.5)$ & - & - & $.385^{*}$ \\
\hline Hypertension & $40(97.5)$ & $76(93.8)$ & - & - & $.663^{*}$ \\
\hline Diabetes & $20(48.8)$ & $57(70.3)$ & - & - & $.028 *$ \\
\hline COPD & $5(12.2)$ & $11(13.6)$ & - & - & $.990^{*}$ \\
\hline Renal disorders & $5(12.2)$ & $20(24.7)$ & - & - & $.154 *$ \\
\hline \multicolumn{6}{|l|}{ Clinical laboratory data } \\
\hline Systolic BP (mm Hg) & $129.8(18.5)$ & $124.2(20.1)$ & $5.6(19.6)$ & $-2.3,13.6$ & $.162 *$ \\
\hline Diastolic BP $(\mathrm{mm} \mathrm{Hg})$ & $72.7(12.6)$ & $71.1(11.2)$ & $1.6(11.6)$ & $-3.2,6.3$ & $.513^{*}$ \\
\hline HGB $(g / d L)$ & $12.6(1.9)$ & $11.6(1.8)$ & $1.0(1.9)$ & $0.24,1.76$ & $.011 *$ \\
\hline RDW (\%) & $13.7(1.2)$ & $14.1(1.4)$ & $-0.4(1.4)$ & $-0.95,0.09$ & $.107^{*}$ \\
\hline $\mathrm{WBC}\left(\times 10^{6} / \mathrm{mL}\right)$ & $12.2(5.1)$ & $10.6(4.6)$ & $1.6(4.8)$ & $-0.38,3.50$ & $.113^{*}$ \\
\hline Platelet $\left(\times 10^{6} / \mathrm{mL}\right)$ & $256.2(73.0)$ & $245.5(77.5)$ & $10.7(76.1)$ & $-20.3,41.7$ & $.495^{*}$ \\
\hline Creatinine (mg/dL) & $1.37(1.75)$ & $1.35(1.52)$ & $0.02(1.61)$ & $-0.62,0.68$ & $.934 * *$ \\
\hline $\mathrm{PT}(\mathrm{s})$ & $12.8(1.1)$ & $12.6(1.4)$ & $0.2(1.3)$ & $-0.43,0.66$ & $.677^{*}$ \\
\hline aPTT (s) & $28.4(5.1)$ & $33.4(12.4)$ & $-5.0(10.6)$ & $-8.4,-1.7$ & $.004^{*}$ \\
\hline
\end{tabular}

Boldface indicates significance. $N o T x$, No red blood cell transfusion(s) during and/or after surgery; $T x$, red blood cell transfusion(s) during and/or after surgery; $S D$, standard deviation; $C I$, confidence interval; $B M I$, body mass index; $C O P D$, chronic obstructive pulmonary disease; $B P$, blood pressure; $H G B$, hemoglobin; $R D W$, red cell distribution width; WBC, white blood cell; $P T$, prothrombin time; $a P T T$, activated partial thromboplastin time. * $t$ test $P$ values. **Mann-Whitney test $P$ value. 
TABLE 2. Presurgery mean levels of different biomarkers by transfusion group

\begin{tabular}{|c|c|c|c|c|c|}
\hline \multirow[b]{2}{*}{ Test } & \multicolumn{2}{|c|}{ NoTx group } & \multicolumn{2}{|c|}{ Tx group } & \multirow[b]{2}{*}{$P$ value* } \\
\hline & Mean (SD) & Median (Q25-Q75) & Mean (SD) & Median (Q25-Q75) & \\
\hline $\mathrm{CD} 42^{+} \mathrm{PMP}(\mathrm{ct} / \mu \mathrm{L})$ & $1279(1138)$ & $958(538-1424)$ & 699 (798) & 467 (287-878) & $<.001$ \\
\hline $\mathrm{CD} 41^{+} \mathrm{PMP}(\mathrm{ct} / \mu \mathrm{L})$ & $24,852(12,749)$ & $24,269(13,247-34,818)$ & $13,507(9766)$ & $10,669(6236-17,233)$ & $<.001$ \\
\hline $\mathrm{CD} 235 \mathrm{a}^{+} \mathrm{RMP}(\mathrm{ct} / \mu \mathrm{L})$ & $2441(1540)$ & 2028 (1483-3299) & 1398 (1124) & $931(576-2079)$ & $<.001$ \\
\hline $\mathrm{CD} 1^{+} \mathrm{EMP}(\mathrm{ct} / \mu \mathrm{L})$ & $675(955)$ & 316 (204-614) & $366(316)$ & $246(157-434)$ & .015 \\
\hline $\mathrm{CD} 2 \mathrm{E}^{+} \mathrm{EMP}(\mathrm{ct} / \mu \mathrm{L})$ & $161(253)$ & $65(16-128)$ & 75 (137) & $23(13-50)$ & .022 \\
\hline $\mathrm{CD}_{144^{+}} \mathrm{EMP}(\mathrm{ct} / \mu \mathrm{L})$ & $317(385)$ & $203(51-428)$ & $228(342)$ & $80(28-319)$ & .062 \\
\hline $\mathrm{CD}_{11 \mathrm{~b}}^{+} \mathrm{LMP}(\mathrm{ct} / \mu \mathrm{L})$ & $1698(3630)$ & $996(567-1447)$ & $868(649)$ & $735(412-1220)$ & .020 \\
\hline $\mathrm{CD} 45^{+} \mathrm{LMP}(\mathrm{ct} / \mu \mathrm{L})$ & $743(436)$ & $703(545-820)$ & $619(365)$ & $640(299-769)$ & .106 \\
\hline Annexin $\mathrm{V}^{+} \mathrm{MP}(\mathrm{ct} / \mu \mathrm{L})$ & 9845 (9603) & $7513(4335-12,118)$ & $6483(6924)$ & 4770 (2889-8293) & .015 \\
\hline $\mathrm{TF}^{+} \mathrm{MP}(\mathrm{ct} / \mu \mathrm{L})$ & $1490(1870)$ & $845(656-1421)$ & $1091(820)$ & 848 (594-1398) & .693 \\
\hline Coagulation index & $1.85(0.98)$ & $1.75(1.13-2.48)$ & $1.56(2.01)$ & $1.90(0.55-2.93)$ & .984 \\
\hline Shear-induced platelet adhesion: SC (\%) & $12.45(5.15)$ & $11.0(7.9-16.0)$ & $11.13(4.39)$ & $11.0(7.7-14.0)$ & .219 \\
\hline 8-Isoprostane (ng/mL) & $123.9(90.6)$ & $94.7(64.3-178.1)$ & $122.0(140.6)$ & $93.5(67.8-143.3)$ & .985 \\
\hline
\end{tabular}

Boldface indicates significance. NoTx, No red blood cell transfusion(s) during and/or after surgery; $T x$, red blood cell transfusion(s) during and/or after surgery; $P M P$, plateletderived microparticle; $S D$, standard deviation; $Q 25-Q 75,25$ th to 75 th percentile; $R M P$, red cell-derived microparticle; $E M P$, endothelium-derived microparticle; $L M P$, leukocytederived microparticle; $M P$, microparticle; $S C$, surface coverage. *Mann-Whitney test $P$ values.

ratio reported corresponds to a change of 1 unit in the given variable, as indicated in column 2 of Tables 3 and 4. For each independent continuous variable with a large range, such as the different biomarkers, the odds ratio was customized to a specific number of units of change by using the UNITS statement in the logistic procedure in SAS (version 9.3, SAS Institute, Inc, Cary, NC). The units were chosen to correspond to approximately 1 standard deviation (SD) of the values reported in the literature as normal values for each biomarker. For example, for $\mathrm{CD} 235 \mathrm{a}^{+}$RMP the odds ratio reported corresponds to a change of $400 / \mu \mathrm{L}$, and for $\mathrm{CD} 41^{+}$PMP the odds ratio reported corresponds to a change of $1100 / \mu \mathrm{L}$.

The statistical analyses were performed using SAS (version 9.3, SAS Institute). Reported in the results are $95 \%$ CIs and $P$ values corresponding to 2-sided hypothesis tests. An alpha level of 5\% was used to assess statistical significance.

\section{RESULTS}

\section{Patient Characteristics}

Presurgical patient characteristics along with medical history and clinical lab data are listed in Table 1. The

TABLE 3. Multiple logistic regression model for assessment of risk factors for transfusion in CABG patients

\begin{tabular}{lcccc}
\hline \multicolumn{1}{c}{ Variable } & $\begin{array}{c}\text { Comparison } \\
\text { or no. of units }\end{array}$ & $\begin{array}{c}\text { Adjusted } \\
\text { OR }\end{array}$ & $\mathbf{9 5 \%}$ CI & $\boldsymbol{P}$ value \\
\hline Gender & Female vs male & 1.62 & $0.34-7.64$ & .546 \\
Blood type & Type O vs other & 1.48 & $0.41-5.32$ & .547 \\
HGB $(\mathrm{g} / \mathrm{dL})$ & 1 & 0.67 & $0.46-0.95$ & $\mathbf{. 0 2 7}$ \\
$\mathrm{aPTT}(\mathrm{s})$ & 1 & 1.17 & $1.00-1.34$ & $\mathbf{. 0 2 0}$ \\
$\mathrm{CD} 42^{+} \mathrm{PMP}(\mathrm{ct} / \mu \mathrm{L})$ & 200 & 0.94 & $0.83-1.07$ & .362 \\
$\mathrm{CD} 41^{+} \mathrm{PMP}(\mathrm{ct} / \mu \mathrm{L})$ & 1100 & 0.90 & $0.85-0.96$ & $\mathbf{. 0 0 1}$ \\
$\mathrm{RMP}(\mathrm{ct} / \mu \mathrm{L})$ & 400 & 0.80 & $0.64-0.99$ & $\mathbf{. 0 3 6}$ \\
$\mathrm{CD} 31^{+} \mathrm{EMP}(\mathrm{ct} / \mu \mathrm{L})$ & 150 & 0.90 & $0.74-1.11$ & .335 \\
$\mathrm{CD} 62 \mathrm{E}^{+} \mathrm{EMP}(\mathrm{ct} / \mu \mathrm{L})$ & 20 & 0.94 & $0.87-1.00$ & .174 \\
Annexin $\mathrm{V}^{+} \mathrm{MP}(\mathrm{ct} / \mu \mathrm{L})$ & 1500 & 1.02 & $0.93-1.12$ & .655 \\
\hline Boldface indicates significance. $O R$, Odds ratio; $C I$, confidence interval; $H G B$, hemo- \\
globin; $a P T T$, activated partial thromboplastin time; $P M P$, platelet-derived micropar- \\
ticle; $R M P$, red cell-derived microparticle; $E M P$, endothelium-derived microparticle; \\
$M P$, microparticle.
\end{tabular}

transfused (Tx) group had a significantly greater proportion of female patients and those with type $\mathrm{O}$ blood and diabetes. There was no significant difference between the Tx and NoTx groups with respect to use of medications, including antiplatelets, antihypertensives, anticoagulants, statins, antidiabetics, antiarrhythmics, etc (data not shown). Patients in the NoTx group had significantly higher levels of HGB and lower aPTT values.

Of central interest to this report are the biomarker data shown in Table 2, which shows, for each biomarker, group-specific mean, SD, median, and 25th (Q25) and 75th (Q75) percentiles. Presurgical mean levels of several types of cell-derived microparticles were significantly higher for patients in the NoTx group compared to those in the Tx group. The most salient differences were those for both phenotypes of plateletderived microparticles $\left(\mathrm{CD} 42^{+}\right.$PMP, $P<.001 ; \mathrm{CD} 41^{+}$ PMP, $P<.001$ ), and red cell-derived microparticles $\left(\mathrm{CD} 235 \mathrm{a}^{+}\right.$RMP, $\left.P<.001\right)$. Differences in EMPs were also significant $\left(\mathrm{CD} 31^{+} \mathrm{EMP}, P=.015\right.$; $\mathrm{CD}^{2} 2 \mathrm{E}^{+} \mathrm{EMP}$, $P=.022$ ), as was the difference for $\mathrm{CD}_{11 \mathrm{~b}^{+} \mathrm{LMP}}$ $(P=.020)$ and annexin $\mathrm{V}^{+}$-derived microparticles $(P=.015)$.

TEG was run for all patients, but no significant difference or interesting trends were observed between the Tx and NoTx groups for any of the TEG parameters $(R, K, A$, MA, and coagulation index). The coagulation index is shown in Table 2 as an example.

\section{Surgery-Related Clinical Data}

We analyzed surgery data and found no significant differences between the NoTx and the Tx groups with respect to: percent of patients on pump, $14.6 \%(6 / 41)$ versus $14.8 \%(12 / 81), P=.979$; percentage of patients with $>2$ vessels grafted, $53.7 \%(22 / 41)$ versus $37 \%$ 
TABLE 4. Final model from stepwise logistic regression for assessment of risk factors for transfusion in CABG patients

\begin{tabular}{lcccccc}
\hline \multicolumn{1}{c}{ Variable } & Units & OR & OR 95 $\%$ CI & $\boldsymbol{P}$ value & AUC \pm SE & AUC 95 $\%$ CI \\
\hline HGB $(\mathrm{g} / \mathrm{dL})$ & 1 & 0.64 & $0.47-0.87$ & $\mathbf{. 0 0 5}$ & $0.66 \pm 0.06$ & $0.55-0.78$ \\
aPTT $(\mathrm{s})$ & 1 & 1.16 & $1.03-1.30$ & $\mathbf{. 0 1 5}$ & $0.68 \pm 0.06$ & $0.57-0.79$ \\
$\mathrm{CD} 41^{+}$PMP $(\mathrm{ct} / \mu \mathrm{L})$ & 1100 & 0.90 & $0.86-0.95$ & $<.001$ & $0.77 \pm 0.05$ & $0.58-0.80$ \\
RMP $(\mathrm{ct} / \mu \mathrm{L})$ & 400 & 0.76 & $0.63-0.92$ & $\mathbf{. 0 0 5}$ & $0.69 \pm 0.06$ & $0.76-0.86$ \\
Model & - & - & - & - & $0.86 \pm 0.04$ & $0.77-0.94$ \\
\hline
\end{tabular}

Boldface indicates significance. $O R$, Odds ratio; $C I$, confidence interval; $A U C$, area under the curve; $S E$, standard error; $H G B$, hemoglobin; $a P T T$, activated partial thromboplastin time; $P M P$, platelet-derived microparticle; $R M P$, red cell-derived microparticle.

(30/81), $P=.080$; and mean number $( \pm \mathrm{SD})$ of platelet units transfused, $1.6 \pm 1.3$ versus $1.5 \pm 1.4, P=.704$.

As expected, the NoTx group had significantly lower means of: estimated blood loss, $448.3 \pm 301.0$ versus $747.0 \pm 676.3 \mathrm{~mL}, P=.009$; cell saver volume, $229.1 \pm 252.3$ versus $570.6 \pm 375.1 \mathrm{~mL}, P<.001 ; \mathrm{RBC}$ transfused units, 0 versus $2.1 \pm 1.6, P<.001$; and plasma transfused units, $0.2 \pm 0.7$ versus $1.1 \pm 1.7, P=.002$.

\section{Risk Assessment Models}

As stated in the methods section, as a first step in the model development process, separate bivariate logistic regression models were considered using as the independent variable each of the variables in Tables 1 and 2 (results not shown). Then, use of multivariate logistic regression resulted in a model (Table 3) with the following 4 independent variables: HGB, aPTT, $\mathrm{CD} 41^{+}$PMP, and CD235a ${ }^{+}$RMP as significant risk factors for transfusion, after adjusting for the effect of the remaining variables in the model.
As a final step in the model-building process, we used a stepwise logistic regression approach. The resulting model (Table 4) showed that HGB, aPTT, CD41 ${ }^{+}$PMP, and $\mathrm{CD} 235 \mathrm{a}^{+} \mathrm{RMP}$ remained as significant risk factors for transfusion. Among these factors, $\mathrm{CD} 41^{+} \mathrm{PMP}$ and CD235 $\mathrm{a}^{+}$RMP appear to have much greater specificity and sensitivity than any other single factor considered.

For each model considered, we assessed the linearity of the logit with respect to each continuous variable and found that the linearity requirement was satisfied without the need for any linearizing transformations (data not shown).

We further assessed the relationship between the predicted probability of transfusion and each variable in Table 4. The scatter plots shown in Figure 1 exhibited a downward trend of probability of transfusion with increasing levels of $\mathrm{HGB}, \mathrm{CD} 41^{+} \mathrm{PMP}$, and $\mathrm{CD} 235 \mathrm{a}^{+}$ RMP and, as expected, an upward trend for aPTTT. It is noted that nearly all $(>95 \%)$ subjects with HGB $<10 \mathrm{~g} / \mathrm{dL}$ or aPTT $>45$ seconds show high probability of transfusion $(>80 \%)$. However, the variability in the
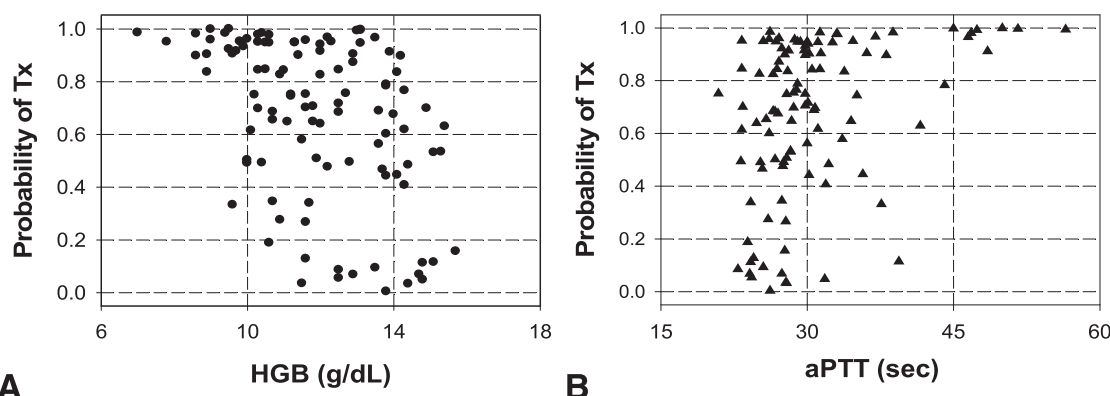

B
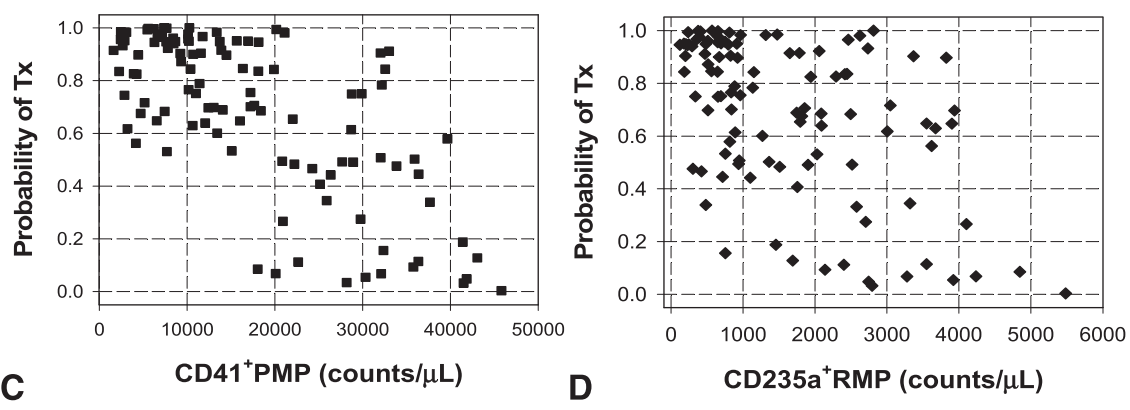

FIGURE 1. Scatter diagrams of probability of transfusion versus (A) HGB, (B) aPTT, (C) CD41 ${ }^{+}$PMP, and (D) CD235a ${ }^{+}$RMP. HGB, Hemoglobin; $a$ PTT, activated partial thromboplastin time; $P M P$, platelet-derived microparticle; $R M P$, red cell-derived microparticle; $T x$, red blood cell transfusion(s) during and/or after surgery. 
probability of transfusion is high when HGB is $>10 \mathrm{~g} / \mathrm{dL}$ or aPTT is $<45$ seconds. In contrast, it is seen that over a wide range of values of $\mathrm{CD} 41^{+} \mathrm{PMP}$ and $\mathrm{CD} 235 \mathrm{a}^{+} \mathrm{RMP}$, the variability in the probability of transfusion is lower. This is also reflected by the coefficients of determination for $\mathrm{CD} 41^{+}$PMP and CD235a $\mathrm{a}^{+} \mathrm{RMP}\left(R^{2}=0.48,0.29\right.$, respectively), as compared to those for HGB and aPTT $\left(R^{2}=0.19,0.14\right.$, respectively $)$.

Finally, we also assessed the accuracy of the models using ROC curve analyses. For each of the variables included in the models presented in Table 4, the AUC and its $95 \% \mathrm{CI}$ are given in the last column of that Table. For the variables in Table 4, the corresponding AUCs range from 0.66 for $\mathrm{HGB}$ to 0.77 for $\mathrm{CD} 41^{+} \mathrm{PMP}$, and all of them are statistically significantly greater than 0.5 .

For the proposed model presented in Table 4, the AUC, its standard error, and the corresponding $95 \% \mathrm{CI}$ are $0.86 \pm 0.04$ and $0.78-0.94$, indicating good discrimination between the Tx and NoTx groups, and correspondingly high sensitivity and specificity. The ROC curve for the proposed model and its 4 components is shown in Figure 2.

\section{DISCUSSION}

The finding of central interest in our analyses is that the NoTx group had significantly higher presurgical microparticle levels compared to the Tx group. The 3 most significant microparticle phenotypes in this respect were the two phenotypes of PMP $\left(\mathrm{CD} 42^{+} \mathrm{PMP}\right.$, $\left.\mathrm{CD} 41^{+} \mathrm{PMP}\right)$ and RMP $\left(\mathrm{CD} 235 \mathrm{a}^{+}\right.$RMP). When considered separately, each of these 3 phenotypes was highly significantly associated with transfusion $(P<.001$, $P<.001$, and $P=.005$, respectively). However, because

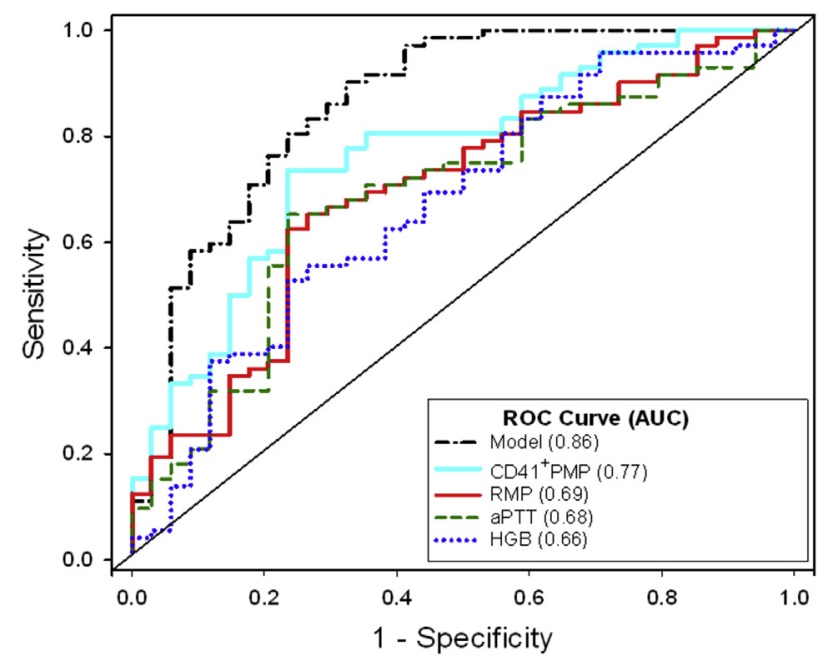

FIGURE 2. Comparison of ROC curve and AUC for CD $41^{+}$PMP, RMP, aPTT, HGB, and combined model. ROC, Receiver operating characteristic; $A U C$, area under the ROC curve; PMP, platelet-derived microparticle; $R M P$, red cell-derived microparticle; $a P T T$, activated partial thromboplastin time; $H G B$, hemoglobin. of the highly significant correlation between the first 2 ( $r=0.58, P<.001$ ), the first one, CD $42^{+}$PMP, became nonsignificant when considered as part of the multivariable models in Tables 3 and 4.

Several precardiac surgery risk factors for transfusion have been reported. ${ }^{8-15}$ Our study results confirm many but not all of them and, more importantly, add some novel findings. We confirmed greater risk for transfusion in female versus male patients, and in type $\mathrm{O}$ blood versus other, as well as in low versus high HGB level. We found here that presurgical aPTT is a risk factor for surgical transfusion but PT is not, a result consistent with the conclusions of Coakley et $\mathrm{al}^{15}$ but not with those of Emeklibas et al, ${ }^{13}$ who reported that presurgical PT values predict transfusion risk. Our data on aPTT should be interpreted with caution because of its low odds ratio (1.15-per-second increment) and marginal significance $(P=.047)$.

The red cell distribution width was recently reported to correlate with major in-hospital transfusion and mortality in coronary surgery patients, ${ }^{21}$ but we found no significant association between preoperative red cell distribution width and transfusion in CABG. Low von Willebrand factor in type $\mathrm{O}$ blood is well known, and this may explain the higher frequency of type $\mathrm{O}$ in the transfusion group in our study. ${ }^{22}$

Laboratory assays to predict surgical transfusion have been described. However, the majority of such studies deal with postsurgical transfusion rather than intraoperative. For example, in $\mathrm{CPB}$, it was found that lower pre-CPB prothrombin fragment $\mathrm{F}^{+} 2$ levels and lower post-CPB platelet counts were associated with post-CPB transfusion. ${ }^{12}$ Other known risk factors for postoperative transfusion in CABG include bleeding history, HGB, adenosine diphosphate-induced platelet aggregation, ${ }^{13}$ maximum amplitude of $\mathrm{TEG},{ }^{14}$ thrombin generation, reduced platelet count, and deficiency of clotting factors (IX, X, XI) ${ }^{15}$ In summary, it appears that assessment of risk for postoperative transfusion has been more successful and has been addressed more frequently in the literature than assessment of risk for intraoperative transfusion.

It is unclear why some patients have high microparticle levels but others do not. Previous studies have shown that microparticles are elevated in thrombotic and inflammatory conditions and cardiovascular disorders (eg, myocardial ischemia, transient ischemic attack, cerebrovascular accident, metabolic syndrome, atherosclerosis, multiple sclerosis, and lupus). It is also known that microparticles are rapidly cleared, presumably by macrophages or the reticuloendothelial system. ${ }^{23-29}$ The elevated microparticle levels in our study may be due to a net effect of excessive rates of microparticle generation and/or decreased microparticle clearance.

It is of interest that unlike gender or blood type, microparticle levels could potentially be manipulated for 
therapeutic purposes by modifying production and/or clearance rates. An increase in patients' presurgical hemostatic microparticle levels could lead to reduction or elimination of their need for transfusion and, therefore, to minimization of the complications associated with transfusion. At the present time, there are no clinically proven methods or products available for this purpose. However, microparticle concentrates made from red cells are being investigated as hemostatic agents and have shown promise in animal models of surgical bleeding. ${ }^{18}$ In other studies, we found preliminary evidence that fresh-frozen plasma may be another source of hemostatic microparticles (unpublished results). We are optimistic that in the near future, these or other options will lead to the safe and effective presurgical elevation of hemostatic microparticle levels for minimizing transfusions.

A limitation of the present study is the relatively small sample size and the inclusion of just a single type of surgery. A larger study not limited to CABG is needed to validate and clarify our findings on presurgical hemostatic microparticle levels as a risk factor for transfusion. If confirmed in other surgical procedures, our results are expected to have a major impact on surgical patient care and transfusion practice.

In summary, this study highlights the importance of microparticles in surgical hemostasis and supports the conclusion that CABG patients with low presurgical microparticle levels are at higher risk for transfusion. We anticipate that the findings reported herein could lead to the development of new strategies to modify levels of microparticles and thereby reduce the risk of excessive surgical bleeding. This, in turn, will translate into substantial reduction in the number of transfusions required and, ultimately, into overall improvement of transfusion practice.

\section{References}

1. Goodnough LR. Blood management: transfusion medicine comes of age. Lancet. 2013;381:1791-2.

2. Loor G, Rajeswaran J, Li L, Sabik JF III, Blackstone EH, McCrae KR, et al. The least of 3 evils: exposure to red blood cell transfusion, anemia, or both? J Thorac Cardiovasc Surg. 2013;146:1480-7.

3. Murphy GJ, Reeves BC, Rogers CA, Rizvi SI, Culliford L, Angelini GD. Increased mortality, postoperative morbidity, and cost after red blood cell transfusion in patients having cardiac surgery. Circulation. 2007;116:2544-52.

4. Koch CG, Li L, Duncan AI, Mihaljevic T, Cosgrove DM, Loop FD, et al. Morbidity and mortality risk associated with red blood cell and bloodcomponent transfusion in isolated coronary artery bypass grafting. Crit Care Med. 2006;34:1608-16.

5. Bhaskkar B, Dulhunty DV, Fraser JF. Impact of blood product transfusion on short and long-term survival after cardiac surgery: more evidence. Ann Thorac Surg. 2012;94:460-7.

6. Paone G, Brewer R, Theurer PF, Bell GF, Cogan CM, Prager RL, Michigan Society of Thoracic and Cardiovascular Surgeons. Preoperative predicted risk does not fully explain the association between red blood cell transfusion and mortality in coronary artery bypass grafting. J Thorac Cardiovasc Surg. 2012; 143:178-85.

7. LaPar DJ, Crosby IK, Ailawadi G, Ad N, Choi E, Spiess BD, et al; Investigators for the Virginia Cardiac Surgery Quality Initiative. Blood product conservation is associated with improved outcomes and reduced costs after cardiac surgery J Thorac Cardiovasc Surg. 2013;145:796-803.

8. Ferranis VA, Gildengonin V. Predictors of excessive blood use after coronary artery bypass grafting. A multivariate analysis. J Thorac Cardiovasc Surg. 1989;98:492-7.

9. Shehata N, Naglie G, Alghamdi AA, Callum J, Mazer CD, Hebert P, et al. Risk factors for red cell transfusion in adults undergoing coronary artery bypass surgery: a systematic review. Vox Sang. 2007;93:1-11.

10. van Straten AH, Kats S, Bekker MW, Verstappen F, ter Woorst JF, van Zundert AJ, et al. Risk factors for red cell transfusion after coronary artery bypass graft surgery. J Cardiothorac Vasc Anesth. 2010;24:413-7.

11. Williams JB, Phillips-Bute B, Bhattachary SD, Shah AA, Amdersen ND Altinase B, et al. Predictors of massive transfusion with thoracic aortic procedures involving deep hypothermic circulatory arrest. J Thorac Cardiovasc Surg. 2011;141:283-8.

12. Karkouti K, McCluskey SA, Syed S, Pazaratz C, Poonawala H, Crowther MA The influence of perioperative coagulation status on postoperative blood loss in complex cardiac surgery: a prospective observational study. Anesth Analg. 2010;110:1533-40.

13. Emeklibas N, Kammerer I, Bach J, Sack F, Hellstern P. Preoperative hemostasis and its association with bleeding and blood component transfusion requirements in cardiopulmonary bypass surgery. Transfusion. 2013;53:1226-34.

14. Wasowicz M, McCluskey SA, Wijeysundera DN, Yau TM, Meinri M Beattie WS, et al. The incremental value of thromboelastography for prediction of excessive blood loss after cardiac surgery: An observational study. Anesth Analg. 2010;111:331-8.

15. Coakley M, Hall JE, Evans C, Duff E, Billing V, Yang L, et al. Assessment of thrombin generation measured before and after cardiopulmonary bypass surgery and its association with postoperative bleeding. J Thromb Haemost. 2011;9: 282-92.

16. Burnier L, Fontana P, Kwak BR, Angelillo-Scherrer A. Cell-derived microparticles in haemostasis and vascular medicine. Thromb Haemost. 2009;101:439-51.

17. Sims PJ, Wiedmer T, Esmon CT, Weiss HJ, Shattil SJ. Assembly of the platelet prothrombinase complex is linked to vesiculation of the platelet plasma membrane. Studies in Scott syndrome: an isolated defect in platelet procoagulant activity. J Biol Chem. 1989;264:17049-57.

18. Jy W, Johansen ME, Bidot C Jr, Horstman LL, Ahn YS. Red cell-derived microparticles (RMP) as haemostatic agent. Thromb Haemost. 2013;110:751-60.

19. Castaman G, Yu-Feng L, Battistin E, Rodeghiero F. Characterization of a novel bleeding disorder with isolated prolonged bleeding time and deficiency of platelet microvesicle generation. Br J Haematol. 1997;96:458-63.

20. Jy W, Horstman LL, Arce M, Ahn YS. Clinical significance of platelet microparticles in autoimmune thrombocytopenias. J Lab Clin Med. 1992;119:334-45.

21. Fatemi O, Torguson R, Chen F, Ahmad S, Badr S, Satler LF, et al. Red cell distribution width as a bleeding predictor after percutaneous coronary intervention. Am Heart J. 2013;166:104-9.

22. Gill JC, Endres-Brooks J, Bauer PJ, Marks WJ Jr, Montgomery RR. Effect of ABO blood group on the diagnosis of von Willebrand disease. Blood. 1987;69: 1691-5.

23. Rand ML, Wang H, Bang KW, Packham MA, Freedman J. Rapid clearance of procoagulant platelet-derived microparticles from the circulation of rabbits. J Thromb Haemost. 2006;4:1621-3.

24. Augustine D, Ayers LV, Lima E, Newton L, Lewandowski AJ, Davis EF, et al Dynamic release and clearance of circulating microparticles during cardiac stress. Circ Res. 2014;114:109-13.

25. Schroit AJ, Madsen JW, Tanaka Y. In vivo recognition and clearance of red cells containing phosphatidylserine in the plasma membrane. J Biol Chem. 1985;265: 5131-8.

26. Ahsan F, Rivas IP, Khan MA, Torres Suarez AI. Targeting to macrophages: role of physicochemical properties of particulate carriers-liposomes and microspheres — on the phagocytosis by macrophages. J Control Release. 2002; 79:29-40.

27. Oldenborg P. Role of CD47 and signal regulatory protein alpha (SIRP alpha) in regulating the clearance of viable or aged blood cells. Trans Med Hemother. 2012;39:315-20.

28. Brück W, Friede RL. Anti-macrophage CR3 antibody blocks myelin phagocytosis by macrophages in vitro. Acta Neuropathol. 1990;80:415-8.

29. Dasgupta SK, Le A, Chavakis T, Dasgupta SK, Le A, Chavakis T, et al Developmental endothelial locus-1 (Del-1) mediates clearance of platelet microparticles by the endothelium. Circulation. 2012;125:1664-72. 